JURNAL PENJAMINAN MUTU
LEMBAGA PENJAMINAN MUTU
INSTITUT HINDU DHARMA NEGERI
DENPASAR $\quad \begin{aligned} & \text { Volume } 6 \text { Nomor } 1 \text { (2020) } \\ & \text { ISSN : 2407-912X (Cetak) } \\ & \text { ISSN : 2548-3110 (Online) } \\ & \text { http://ejournal.ihdn.ac.id/index.php/JPM }\end{aligned}$

\title{
PENINGKATAN MUTU PENDIDIKAN HINDU MELALUI PENGELOLAAN PEMBELAJARAN
}

\author{
Oleh \\ I Putu Widyanto \\ Institut Agama Hindu Negeri Tampung Penyang Palangka Raya \\ putuwidyanto@gmail.com
}

diterima 14 November 2019, direvisi 11 Pebruari 2020, diterbitkan 29 Pebruari 2020

\begin{abstract}
Hindu Education Institution is one of Education Institution which has responsibility in establishing and improving Hindu's Human Resource quality to obtain competitiveness in facing globalization challenge. In the process of Hindu Education learning, still widely found the educator using TeacherCentered Learning Approach which is makes students less actively involved in the learning process. This research aims to generate a synthesis concerning Hindu Education Learning management which can accomplish the qualification of graduate abilities which has been determined by the government. The study uses a qualitative research approach to the type of library research. The existence of Hindu education, in it's role of engender the young Hindu generation who is ready to deal with global challenge, should be able to organize the process of debriefing with presenting education which integrate intellectuality, creativity, spirituality, and morality in its education system, and refer to the Hindu value with applying the Student-Centered Learning approach alongside learning management principal.
\end{abstract}

\section{Keywords: Hindu Education Management, Learning Management, Teacher Centered Learning, Student Centered Learning.}

\begin{abstract}
Abstrak
Lembaga pendidikan Hindu merupakan salah satu lembaga pendidikan yang memiliki tanggung jawab membangun dan meningkatkan kualitas SDM Hindu agar memiliki daya saing dalam menghadapi tantangan globalisasi. Dalam proses pembelajaran pendidikan Hindu, masih banyak ditemui pendidik menggunakan pendekatan pembelajaran Teacher Centered Learning yang merupakan pendekatan yang kurang membuat peserta didik terlibat aktif di dalam proses pembelajarannya. Tujuan penelitian ini dapat menghasilkan sebuah sintesa mengenai pengelolaan pembelajaran pendidikan Hindu yang dapat memenuhi kualifikasi kemampuan lulusan yang sudah ditetapkan oleh pemerintah. Penelitian menggunakan pendekatan penelitian kualitatif dengan
\end{abstract}


jenis penelitian kepustakaan (Library Research). Kehadiran pendidikan Hindu dalam perannya melahirkan generasi muda Hindu yang siap menghadapi tantangan global harus mampu menyelenggarakan proses pembekalan dengan menghadirkan pendidikan yang memadukan intelektualitas, kreativitas, sprtitualitas dan moralitas dalam sistem pendidikannya, dan mengacu kepada nilai-nilai Hindu menggunakan pendekatan pembelajaran Student Centered Learning dengan menerapkan prinsif manajemen pembelajaran.

Kata Kunci : Pengelolaan Pendidikan Hindu, Pengelolaan Pembelajaran, Teacher Centered Learning, Student Centered Learning.

\section{PENDAHULUAN}

Perubahan kondisi masyarakat saat ini merupakan bagian tidak terpisahkan dari arus globalisasi yang telah merambah ke seluruh aspek kehidupan, dimana saat ini sedang memasuki babak baru perkembangan globalisasi yaitu globalisasi budaya (Fathurrohman, 2017:48). Fase globalisasi yang dimulai dari globalisasi politik dimana berdirinya PBB tahun 1945, selanjutnya tahun 1970 an muncul globalisasi ekonomi karena adanya pasar bebas, kemudian tahun 2000 an, hadir globalisasi budaya yang ditandai makin mudah dan cepatnya akses informasi dan komunikasi sehingga memudahkan antar bangsa saling sharing informasi (Wayong, 2017:219). Globalisasi merupakan saling keterhubungan antar manusia melalui investasi, perdagangan, perjalanan dan interaksi lainnya sehingga tidak adanya jarak lagi (Nurhaidah, 2015:1), sehingga proses penyebaran hal baru yang ada di dunia sangat cepat (Wayong, 2017:220).

Pendidikan Hindu seharusnya dapat memainkan posisi yang penting untuk mempersiapkan generasi muda Hindu menghadapi era yang penuh dengan tantangan globalisasi. Pendidikan Hindu harus mampu menyelenggarakan proses pembekalan pengetahuan agama Hindu, pengetahuan umum, meningkatkan kreativitas, penanaman nilai, pembentukan sikap dan karakter, pengembangan bakat, kemampuan dan keterampilan sesuai dengan tuntutan zaman (Fathurrohman, 2017:49), sehingga pendidikan Hindu dengan nilainilai Hindunya dapat digunakan sebagai landasan dalam mengantisipasi tantangan era globalisasi saat ini.

Proses tersebut dapat dicapai dengan menciptaan kondisi pembelajaran yang tepat sehingga berdampak ketercapaian tingkat kedewasaan secara fisik, sosial, spikologi emosional, ekonomi, moral dan spiritual peserta didik, serta penciptaan kondisi tersebut akan membuat respon peserta didik pada interaksi oleh pendidik cukup positif, peserta didik akan lebih termotivasi dan percaya diri untuk aktif (Wachyudi, Srisudarso, \& Miftakh, 2015: 40-49). Kegiatan pembelajaran merupakan kegiatan yang paling utama dari seluruh proses pendidikan, dimana proses pembelajaran sangat menentukan capaian tujuan pendidikan (Dewi, Tripalupi, \& Artana, 2013:2).

Lembaga pendidikan Hindu salah satu lembaga pendidikan yang memiliki tanggung jawab membangun dan meningkatkan kualitas SDM Hindu agar memiliki daya saing dalam menghadapi tantangan globalisasi. Dalam proses pembelajaran pendidikan Hindu, masih banyak ditemui pendidik menggunakan paradigma konvensional, yaitu paradigma 'guru menjelaskan - murid mendengarkan' atau pendekatan pembelajaran Teacher Centered Learning/TCL. Metode pembelajaran TCL telah menjadikan pembelajaran membosankan, tidak membuat peserta didik ikut terlibat aktif di dalam proses pembelajarannya (Subakti, 2010:3). TCL merupakan pendekatan proses pembelajaran yang memandang semua peserta didik sama. Proses pembelajaran yang terjadi seharusnya 
menggunakan pendekatan konstruksivisme, dimana proses pembelajaran menekankan bahwa peserta didik dalam proses pembelajaran memiliki sikap aktif untuk membangun pengetahuan secara individu, dan bukan hanya menerima informasi yang didapatkannya (Antika, 2014:253).

Standar kompetensi lulusan tingkat satuan pendidikan menurut permendikbud No. 20 Tahun 2016 tentang standar kompetensi lulusan pendidikan dasar dan menengah dan standar kompetensi lulusan tingkat pendidikan tinggi menurut Permenristekdikti No 44 Tahun 2015 Tentang SNPT harus memenuhi kemampuan lulusan yang mencakup sikap, keterampilan dan pengetahuan, sedangkan untuk menuntaskan standar kompetensi lulusan ini dibutuhkan pendekatan pembelajaran yang tepat sebagai prinsip utama yaitu pendekatan berpusat kepada siswa atau Student Centered Learning/SCL (Ramadhani, 2017:68). Student Centred Learning merupakan pendekatan pembelajaran di mana peserta didik menjadi fokus dalam pembelajaran, dimana SCL berasal dari teori pembelajaran Konstruktivis (Susanti, 2015:585). Teori belajar konstruktivistik pertama kali disampaikan oleh Piaget, Vygotsky dan Bruner dengan pendapat dimana pemahaman dan pengetahuan diperoleh dengan aktif melalui pengalaman peserda didik serta aktivitas eksperimental (Rusman, 2017: 112). Peserta didik menggunakan pengalaman dan merefleksikan pengalamannya tersebut untuk membentuk struktur pengetahuan yang baru (Nurohman, 2008: 134), berdasarkan pengetahuan yang dimilikinya melalui tindakan dan interaksi dengan lingkungannya. Pembentukan kelompok kecil dalam pembelajaran memungkinkan peserta didik dapat berinteraksi dengan yang lain, bertukar pengalaman dan membantu mengecek pemahaman tentang konsep yang telah ada sebelumnya (Rudiyanto \& Waluya, 2010: 35).

Pengelolaan pendidikan Hindu sudah harus mulai berbenah untuk menghadapi tantangan globalisasi. Pembenahan tersebut dapat dimulai dari pengelolaan sistem pembelajaran yang tepat sesuai dengan prinsif konstruktivisme dengan harapan kompetensi lulusan pendidikan tingkat dasar, menengah dan pendidikan tinggi Hindu dapat memenuhi kualifikasi lulusan mencakup aspek sikap, pengetahuan dan keterampilan, diharapkan tujuan penelitian ini dapat menghasilkan sebuah sintesa mengenai pengelolaan pembelajaran pendidikan Hindu yang dapat memenuhi standar kemampuan lulusan.

\section{METODE}

Penelitian menggunakan pendekatan penelitian kualitatif dengan jenis penelitian kepustakaan (Library Research). Penelitian kepustakaan merupakan kajian teoritis terhadap referensi serta literatur ilmiah lainnya yang berkaitan dengan masalah yang ingin dipecahkan peneliti ( $\mathrm{T} \&$ \& Purwoko, 2018:3).

Tahapan penelitian kepustakaan dimulai dari peneliti memilih topik penelitian, mengeksplorasi informasi, menetapkan fokus penelitian, pengumpulan data, melakukan analisis data dan penyajian data. Sumber data yang digunakan berupa buku dan jurnal ilmiah yang terkait dengan judul yang telah dipilih. Teknik pengumpulan data dengan teknik dokumentasi menggunakan instrument penelitian berupa daftar check-list klasifikasi bahan penelitian yang diperlukan. Analisis data menggunakan teknik analisis isi, sedangkan untuk menjaga keabsahan hasil penelitian menggunakan pengecekan dengan pustaka laiinya dan pengecekan oleh pembimbing.

\section{PEMBAHASAN}

\section{Pengelolaan Pendidikan Hindu}

Pendidikan merupakan pembentukan kemampuan intelektual, dan emosional peserta didik (Faturrahman, 2012:4), yang bertujuan membangun manusia seutuhnya baik fisik maupun karakternya, sehingga menjadi peserta didik yang mempunyai karakter dan keterampilan yang dapat digunakan untuk kehidupan dimasyarakat dan bernegara (Machwe, 2000:165). 
Pendidikan merupakan perwujutan interaktif yang dilakukan dua orang atau lebih secara sadar dan terencana, dimana pendidik berperan sebagai dinamisator dan fasilitator sedangkan peserta didik mengembangkan diri melalui wadah berupa lembaga pendidikan (Rohman, 2009:10), khususnya sekolah dan perguruan tinggi, yang tidak hanya bertugas memelihara dan meneruskan tradisi yang sudah ada tetapi juga mau berkembang mengikuti perubahan kondisi di masyarakat, sebab mengelola pendidikan pada hakikatnya adalah mengelola masa depan (Fadjar, 2005:67).

Pendidikan Hindu di Indonesia melalui PMA No. 56 Tahun 2014 Tentang Pendidikan keagamaan Hindu terbagi menjadi pendidikan formal dan noformal dalam wadah pasraman. Pasraman Formal merupakan jalur pendidikan berjenjang dan terstruktur, meliputi pendidikan dasar (Pratama Widya Pasraman, Adi Widya Pasraman dan Madyama Widya Pasraman) pendidikan menengah (Utama Widya Pasraman) dan pendidikan tinggi (Maha Widya Pasraman). Sedangkan Pasraman Nonformal merupakan jenjang pendidikan yang dilaksanakan secara dalam bentuk $\mathrm{Sad}$ Dharma, Pesantian, Padepokan, Parampara, Aguron guron, Gurukula, dan sejenisnya. Pendidikan Hindu yang dilaksanakan di sekolah umum atau pendidikan tinggi umum berupa pemberian pembelajaran pendidikan Hindu dan pendidikan budi pekerti kepada peserta didik yang beragama Hindu pada tingkat satuan pendidikan dan mata kuliah pendidikan agama Hindu untuk pendidikan tinggi.

Penyelenggaraan pendidikan Hindu tingkat pendidikan tinggi di Indonesia berupa perguruan tinggi agama dalam bentuk sekolah tinggi, institut dan universitas yang diselenggarakan oleh pemerintah maupun swasta. Perguruan tinggi agama sebagai lembaga pendidikan mempunyai peran dan tanggung jawab yang strategis dalam pembangunan suatu bangsa, termasuk memecahkan masalah pendidikan. Peran perguruan tinggi agama yang tercermin dalam Tri Dharma Perguruan Tinggi yaitu pendidikan, penelitian, dan pengabdian kepada masyarakat yang dapat membantu mengembangkan konsep dan strategi pendidikan yang dilakukan dengan pola kerja sama antar pembuat kebijakan pendidikan dan dunia industri. (Amri, 2013:69). Pendidikan Hindu baik dalam bentuk pasraman, pendidikan agama Hindu di pendidikan umum maupun di perguruan tinggi agama, memiliki peran menghasilkan lulusan yang berkualitas secara intelektual, professional dan memiliki karakter yang agamais, menghasilkan iptek memiliki kemampuan memecahkan masalah yang ada di masyarakat (Soedijarto, 2008:220). Peranan pendidikan Hindu menjadi sangat penting saat ini dimana tuntutan peningkatan SDM yang berkualitas dan memiliki karakter agar dapat memenuhi kualifikasi yang diinginkan oleh masyarakat. Pendidikan Hindu memiliki peran serta dalam membentuk karakter, mencerdaskan serta membangun bangsa, maka pendidikan Hindu haruslah memiliki pengelolaan pendidikan yang baik untuk mengatasi setiap tantangan dan hambatan di tengah perubahan yang terjadi.

Tantangan yang dialami pendidikan Hindu salah satunya adalah perkembangan ilmu pengetahuan dan teknologi, perubahan sosial budaya masyarakat, kebijakan sistem pendidikan, serta meningkatnya harapan dari pengguna lulusan terhadap kualitas mutu dan pelayanan dari penyelenggara pendidikan Hindu, tantangan tersebut menuntut pendidikan tinggi untuk terus berkembang menjadi lebih baik. Tantangan lain yang dihadapi penyelenggara pendidikan Hindu adalah tantangan terhadap persaingan antar pendidikan agama lain untuk saling berlomba menghasilkan SDM yang berkulitas. Dimana pendidikan agama yang terus berkembang meningkatkan kulitasnya akan mampu terus bertahan.

\section{Peran Penting Pembelajaran dalam Pengelolaan Pendidikan}

Pendidikan abad 21 hendaknya mampu menghasilkan SDM yang mempunyai kompetensi dimana kompetensi tersebut 
antara lain : Kompetensi pemahaman yang baik, kemampuan berkolaborasi, kemampuan berpikir kritis dan berkomunikasi (Abidin, 2016:8). Kemampuan pemahaman yang baik, kemampuan berkolaborasi, kemampuan berpikir kritis dan berkomunikasi, kemampuan berpikir kritis (Morocco, 2008:5). Keterampilan belajar dan inovasi (kemampuan berpikir kreatif , kemampuan memecahkan masalah , kemampuan berkolaborasi dan berkomunikasi), Keterampilan dalam penguasaan media TIK, keterampilan dalam menjalankan kehidupan dan berkarir (Trilling \& Fadel, 2009:48). Kompetensi tersebut hanya dapat dilakukan melalui proses pembelajaran yang tepat.

Proses pembelajaran merupakan perubahan tingkah laku seseorang akibat pengalaman yang menyangkut aspek fisik maupun psikis, seperti dari tidak mengetahui menjadi mengetahui tentang sesuatu, (Syarifuddin, 2011: 113-136). Pembelajaran adalah aktivitas peserta didik untuk mencapai hasil belajar dengan motivasi pendidik (Abidin, 2016:6). Sehingga tanpa adanya aktivitas peserta didik proses pembelajaran belum dimulai. Selama proses pembelajaran terjadi interaksi antar lingkungan pembelajaran sehingga membuat suatu proses penyesuaian diri peserta didik dengan lingkungan belajarnya, dengan penyesuaian diri tersebut terjadi perubahan pada diri peserta didik sehingga akan menentukan cara pandang peserta didik terhadap suatu hal yang dihadapinya.

Pengelolaan pembelajaran yang sesuai akan memberikan perubahan bagi peserta didik seperti mengembangkan kreativitas, berpikir kritis, analitik dan dapat meningkatkan kemampuan mengkonstruksi pengetahuan baru selain itu dapat meningkatkan kemampuan untuk memahami dan memecahkan masalah di lingkungannya dan meningkatkan keterampilan komunikasi dan kerja sama antar teman (Zakaria \& Awaisu, 2011: 1), proses tersebut dapat diperoleh dengan membuat suasana proses pembelajaran yang kondusif sehingga berdampak ketercapaian tingkat kedewasaan secara psikologis, fisik, sosial, emosional, moral, spiritual dan ekonomi peserta didik. Kegiatan pembelajaran direncanakan untuk menghadirkan pengalaman belajar kepada peserta didik melalui interaksi dengan lingkungan belajarnya dalam rangka mencapaian capaian pembelajaran (Rusman, 2017: 85). Pendapat tersebut sesuai hasil penelitian Sidek \& Yunus, (2012: 135-143), pembelajaran yang mengikutsertakan peserta didik secara aktif akan berdampak memberikan pengalaman belajar lebih banyak sehingga capaian pembelajaran yang direncanakan dapat terwujud.

\section{Pembelajaran Pendidikan Hindu \& Tantangan}

Berdasarkan UU Sisdiknas No. 20

Tahun 2003 pendidikan sebagai upaya menghadirkan proses pembelajaran maupun suasana belajar agar peserta didik aktif mengembangkan potensi yang dimilikinya untuk memiliki kekuatan spiritual keagamaan, akhlak mulia, pengendalian diri, kecerdasan, kepribadian serta keterampilan yang diperlukan dirinya masyarakat bangsa, dan negara. Sedangkan makna dari pendidikan Hindu itu sendiri merupakan sebuah upaya yang terencana untuk mewujudkan nilai-nilai Hindu baik dalam bentuk lembaga penyelenggaraannya maupun dalam kegiatan-kegiatan yang diselenggarakannya untuk mewujudkan proses pembelajaran dan suasana belajar. Dengan kata lain menempatkan nilai-nilai Hindu sebagai pondasi dasar penyelenggaraan pendidikan.

Kurikulum sebagai pedoman untuk penyelenggaraan proses pembelajaran merupakan hal penting dalam pengelolaan pendidikan. Melalui Kurikulum 2013 untuk satuan pendidikan dan Kurikulum Berbasis KKNI untuk perguruan tinggi merupakan upaya pemerintah melalui pengembangan kurikulum untuk mempersiapkan SDM agar siap menghadapi tantangan globalisasi. Tetapi setelah pelaksanaan kurikulum 2013 dan KKNI dilaksanakan ditemukan beberapa kendala diantaranya kesiapan tenaga pengajar dalam mengimplementasikannya seperti pemahaman dan kompetensi tenaga 
pengajar tersebut (Apri \& Rusmawan, 2015:464), seperti pembuatan perangkat pembelajaran, implementasi dan penilaian (Ruja \& Sukamto, 2015:193), sehingga mayoritas kendala yang dihadapi adalah di saat proses pembelajaran baik saat perencanaan, pelaksanaan dan Evaluasi.

Sistem pengelolaan pendidikan di Indonesia lebih menekankan pengetahuan dan kurang pada pengembangan bakat kreatif dan sikap/karakter peserta didik. Padahal kreativitas, pengetahuan dan sikap/karakter bermanfaat dalam pengembangan diri peserta didik yang dapat digunakan sebagai bekal menghadapi tantangan globalisasi (Rusniati, 2015:107). Sistem pendidikan Hindu saat ini lebih banyak menekankan pada pembelajaran pengetahuan ketuhanan (kebenaran/ spiritualitas) sebagai pembangunan manusia dari dalam diri (Surpi, 2017:173), sedangkan berdasarkan hasil penelitian Sutriyanti mengungkapkan pembelajaran pendidikan agama Hindu di kota Denpasar kurang mengembangkan kreativitas siswa selama proses pembelajaran dan lebih Teacher Centered Learning/TCL atau pendidik lebih dominan selama proses pembelajaran dengan menggunakan strategi pembelajaran seperti dharma tula, dharma wacana, dharma gita, dharma yatra, dharma shanti, dharma sadhana (Sutriyanti, 2017:97-113).

Model TCL termasuk dalam model konvensional yang banyak digunakan untuk menyampaikan materi pembelajaran yang membutuhkan uraian atau penjelasan secara lisan, pada umumnya ketika pendidik melakukan model TCL juga diselingi tanya jawab (Sunarti, 2013: 74). Keberhasilan model TCL tergantung dari kemampuan dan gaya berkomunikasi pendidik serta media yang digunakan sebagai alat bantu pembelajaran sehingga menghasilkan pembelajaran yang menarik bagi peserta didik (Guspita, 2017: 39). Salah satu kelebihan model TCL adalah lebih sederhana dalam proses perencanaan maupun pelaksanaan dan sangat efektif dalam upaya menyampaian informasi dengan cepat kepada kelompok sasaran yang berjumlah besar (Hidayati, Salawat, \& Istiana, 2012: 3), selain itu melalui TCL pendidik dapat mengontrol keadaan kelas, oleh karena sepenuhnya kelas merupakan tanggung jawab pendidik dan organisasi kelas dapat diatur menjadi lebih sederhana (Fahruddin, Nyeneng, \& Viyanti, 2014: 44).

Model TCL juga memiliki kekurangan antara lain bila model TCL selalu digunakan akan membuat pembelajaran menjadi membosankan, karena pembelajaran bersifat satu arah maka peserta didik menjadi pasif (Puryanti \& Maryamah, 2015: 311), dan peserta didik akan kesulitan untuk menangkap makna esensi materi pembelajaran, karena kegiatannya sebatas membuat catatan analisis materi dari tenga pendidik, selain itu efektivitas pembelajaran menjadi sangat rendah dan tidak menumbuhkan kreativitas dan partisipasi aktif dalam pembelajaran (Sutrisno \& Suyadi, 2016: 111). Dalam pendekatan tersebut pendidik menempatkan diri sebagai sumber utama informasi dan peran peserta didik hanya melakukan aktivitas sesuai dengan petunjuk pendidik, peserta didik kurang diberi kesempatan untuk melakukan aktivitas sesuai minat dan keinginan (Rusman, 2017: 210).

Pendidikan Hindu seharusnya pendidikan yang memadukan dan tidak memisahkan intelektualitas, kreativitas, sprtitualitas dan moralitas dalam sistem pendidikannya, dan mengacu kepada nilainilai Hindu dengan menggunakan pendekatan pembelajaran Student Centered Learning/SCL atau lebih menekankan pada bagaimana peserta didik diberi kesempatan untuk membangun pengetahuannya sendiri sehingga dapat memperoleh pemahaman yang baik sehingga meningkatkan kualitasnya (Ardian \& Munadi, 2015:455).

\section{Pengelolaan Pembelajaran Pendidikan Hindu}

Pembelajaran berdasarkan paradigma konstruktivistik lebih mengedepankan mengembangkan konsep, penyelesaian masalah, konstruksi solusi, dan algoritme serta menggunakannnya untuk mendapatkan jawaban benar. Pembelajaran 
mengedepankan investigasi, hipotesis, aktivitas eksperimentasi dan pertanyaanpertanyaan (Rusman, 2017: 114), dengan kata lain peran aktif peserta didik sangat dibutuhkan selama proses pembelajaran sedangkan peran pendidik sebagai fasilitator dan motivator selama proses pembelajaran (Kosasih, 2014:74).

Proses pembelajaran di pendidikan Hindu dapat terlaksana secara efektif bila didukung manajemen yang efektif (Manullang, 2014: 210), karena tanpa manajemen yang efektif proses pembelajaran di pendidikan Hindu tidak dapat dilaksanakan secara optimal, efektif dan efisien (Rukayah \& Ismanto, 2016: 178). Fungsi perencanaan, pelaksanaan, dan pengawasan merupakan fungsi manajemen yang digunakan pendidik dalam melaksanakan pembelajaran (Davies, 2007: 310).

Perencanaan pembelajaran merupakan pengambilan keputusan atas berbagai pilihan prosedur instruksional untuk mencapai tujuan yang telah ditentukan, (Suryapermana, 2017: 183), sehingga perubahan tingkah laku yang diharapkan pada diri peserta didik terjadi (Widyanto, Slamet, \& Prihatin, 2018:242). Dalam perencanaan pembelajaran pendidik melakukan proses perumusan RPP/RPS dan penyusunan perangkat pembelajaran, (Nadzir, 2013:339). RPP/RPS dan perangkat pembelajaran yang telah dibuat akan di evaluasi oleh program studi. Pengawasan terhadap proses perencanaan melalui program studi sangatlah penting karena pengawasan meliputi pengecekan program apa berjalan sesuai rencana yang ditetapkan (Sagala, 2011: 65).

\section{Perumusan RPP/RPS harus}

memperhatikan beberapa hal antara lain (1) Pertama, capaian pembelajaran lulusan. Proses pembelajaran yang baik adalah proses pembelajaran yang memberikan peserta didik pengalaman belajar secara bermakna kepada peserta didik untuk membuka keunikan potensi dirinya dalam menginternalisasikan pengetahuan, keterampilan dan sikap (Sutrisno \& Suyadi, 2016: 110); (2) pendekatan pembelajaran. Pembelajaran yang melibatkan peserta didik secara aktif berdampak memberikan pengalaman belajar lebih banyak kepada peserta didik (Sidek \& Yunus, 2012: 135-143), (3) strategi pembelajaran. Penggunaan strategi yang tidak sesuai dengan capaian pembelajaran membuat tujuan yang telah dirumuskan sulit tercapai karena setiap strategi pembelajaran memiliki keunggulannya, oleh sebab itu pemahaman pendidik dalam memilih strategi pembelajaran sangat penting sebelum memutuskan strategi mana yang akan dipakai selain pertimbangan capaian pembelajaran yang akan dituju (Samiudin, 2016: 119), salah satu strategi pembelajaran yang melibatkan peserta didik secara aktif adalah inkuiri, discovery, pembelajaran berbasis masalah, pembelajaran berbasis proyek dan strategi pembelajaran lainnya; (4) prinsip penilaian. Penilaian hendaknya berorientasi pada ketercapaian pembelajaran, bukan vonis terhadap kesalahan artinya, penilaian masih bisa berubah selagi peserta didik bersedia memperbaiki proses dan hasil belajarnya sepanjang proses pembelajaran, hal ini sulit dilakukan bila sistem penilaian masih hanya menggunakan sistem UTS, UAS dan tugas (Sutrisno \& Suyadi, 2016: 162). Prinsip penilaian yang tepat adalah penilaian otentik. Penilaian otentik adalah pengukuran atas hasil belajar peserta didik yang bermakna dan secara signifikan (Putra, 2015: 208), untuk menilai kesiapan peserta didik, proses, dan hasil belajar secara utuh, penilaian hasil belajar harus dilakukan dengan menyeimbangkan cakupan aspek sikap, pengetahuan, dan keterampilan secara menyeluruh (Susanti, 2016: 56).

Pelaksanaan pembelajaran merupakan implementasi dari perencanaan pembelajaran (Rusman, 2017: 70), atau penerapan secara nyata rencana pembelajaran yang telah dibuat oeh pendidik (Novalita, 2014: 59), dimana pelaksanaan pembelajaran merupakan salah satu faktor eksternal yang mempengaruhi hasil belajar, jika pelaksanaan pembelajaran baik, maka tujuan pembelajaran akan tercapai dengan baik (Dewi et al., 2013:1). Proses pelaksanaan pembelajaran berhubungan dengan 
mengkondisikan lingkungan yang membuat peserta didik belajar secara aktif, sebagai upaya menciptakan suasana pembelajaran yang kondusif diperlukan keterampilan mengelola kelas dengan baik (Rahayu, 2015: 359). Keterampilan tersebut merupakan keterampilan pendidik untuk menciptakan, memelihara dan mengendalikan kondisi belajar yang optimal (Hasibuan \& Moedjiono, 2010: 82). Pelaksanaan pembelajaran terbagi menjadi beberapa tahapan antara lain (1) tahap awal, yakni tahap memulai proses belajar-mengajar, (2) tahap inti, yakni tahap pemberian bahan pelajaran yang dapat diidentifikasikan dengan beberapa kegiatan, dan (3) tahap penutup, yaitu tahap evaluasi atau tindak lanjut tahap inti (Rahayu, 2015: 359).

Pengawasan adalah mengukur dan melakukan perbaikan terhadap segenap aktivitas pembelajaran untuk memastikan tujuan terlaksanakan (Kurniadin \& Machali, 2012: 132). Pengawasan proses pembelajaran dilakukan melalui kegiatan pemantauan, supervisi, evaluasi, pelaporan, serta tindak lanjut secara berkala dan berkelanjutan (S, Usman, \& Niswanto, 2017: B155), yang dilakukan secara internal maupun secara eksternal (Ikhwan, 2016: 130), internal oleh pendidik terhadap pelaksanaan pembelajaran dikelas yang menekankan pada pemberian bantuan kepada mahasiswa dalam mengidentifikasikan sekaligus mendorong perbaikan, sedangkan eksternal oleh prodi, P2M, kepala sekolah dan pengawas terhadap kinerja pendidik terhadap pelaksanaan pembelajaran untuk mencocokkan apakah kegiatan pelaksanaan pembelajaran sesuai dengan rencana yang telah ditetapkan dalam mencapai tujuan dari institusi pendidikan (Widyanto, 2019:92-93).

\section{SIMPULAN}

Pendidikan Hindu sudah saatnya dapat memainkan peranan yang sangat penting dalam mempersiapkan generasi muda Hindu menghadapi era yang penuh dengan tantangan globalisasi, dengan menghadirkan pendidikan yang memadukan intelektualitas, kreativitas, sprtitualitas dan moralitas dalam sistem pendidikannya, dan mengacu kepada nilai-nilai Hindu menggunakan pendekatan pembelajaran Student Centered Learning dengan menerapkan prinsif manajemen pembelajaran

\section{DAFTAR PUSTAKA}

Abidin, Y. (2016). Desain Sistem Pembelajaran dalam Konteks Kurikulum 2013. Bandung: Rafika Aditama.

Antika, R. R. (2014). Proses Pembelajaran Berbasis Student Centered Learning (Studi Deskriptif di Sekolah Menengah Pertama Islam Baitul 'Izzah, Nganjuk ). BioKultur, 3(1), 251-263. Retrieved from http://journal.unair.ac.id/filerPDF/bk 21a95d451ffull.pdf

Apri, D. S. K., \& Rusmawan. (2015). Kendala Guru Sekolah Dasar Dalam Implementasi Kurikulum 2013. Cakrawala Pendidikan, Th. XXXIV,(3), 457-467. Retrieved from https://media.neliti.com/media/public ations/82440-none-71a2ca0e.pdf

Ardian, A., \& Munadi, S. (2015). Pengaruh Strategi Pembelajaran Student Centered Learning dan Kemampuan Spasial Terhadap Kreativitas Mahasiswa. Jurnal Pendidikan Teknologi Dan Kejuruan, 22(4), 454466.

https://doi.org/10.21831/jptk.v22i4.7 843

Davies, E. (2007). The Training Manager's Desktop Guide. In Journal of Experimental Psychology: General (Vol. 136). London: Thorogood Publishing Ltd.

Dewi, N. G. A. A. L., Tripalupi, L. E., \& Artana, M. (2013). Pengaruh pelaksanaan pembelajaran dan kebiasaan belajar terhadap hasil belajar ekonomi kelas x sma lab singaraja 1. Jurnal Jurusan Pendidikan Ekonomi, 3(1). Retrieved from https://ejournal.undiksha.ac.id/index. php/JJPE/article/view/1276/1137 
Fadjar, A. M. (2005). Holistika Pemikiran Pendidikan. Jakarta: Raja Grafinda Persada.

Fahruddin, Nyeneng, I. D. P., \& Viyanti. (2014). Perbandingan Hasil Belajar Metode Diskusi Berbasis Keterampilan Generik Sains Dengan Metode Ceramah. Jurnal Pembelajaran Fisika, 2(3). Retrieved from

http://jurnal.fkip.unila.ac.id/index.ph $\mathrm{p} / \mathrm{JPF} /$ article/view/4587

Fathurrohman, N. (2017). Orientasi Dan Strategi Pendidikan Dalam Mengahadapi Era Globalisasi. Wahana Karya Ilmiah Pendidikan, 1(1). Retrieved from https://journal.unsika.ac.id/index.php/ pendidikan/article/view/785

Faturrahman. (2012). Pengantar Pendidikan. Jakarta: Prestasi Pustaka Publisher.

Guspita, H. (2017). Efektivitas Promosi Kesehatan menggunakan Metode Ceramah tentang HIV/AIDS terhadap Pengetahuan dan Sikap Remaja di SMK Tritech Informatika dan SMK Namira Tech Nusantara Medan tahun 2016. Jurnal Ilman, 5(1), 33-40. Retrieved from https://journals.synthesispublication.o rg/index.php/Ilman/article/download/ $24 / 22$

Hasibuan, J. J., \& Moedjiono. (2010). Proses Belajar Mengajar. Bandung: Remaja Rosdakarya.

Hidayati, A., Salawat, T., \& Istiana, S. (2012). Pengaruh Pendidikan Kesehatan Melalui Metode Ceramah Dan Demonstrasi Dalam Meningkatkan Pengetahuan Tentang Kanker Payudara dan Ketrampilan Praktik Sadari (Studi pada Siswi SMA Futuhiyyah Mranggen Kabupaten Demak). Jurnal Kebidanan Universitas Muhammadiyah Semarang, 1(1). Retrieved from https://journals.synthesispublication.o rg/index.php/Ilman/article/download/ $24 / 22$
Ikhwan, A. (2016). Manajemen Perencanaan Pendidikan Islam. Edukasi, 04(01), 128-155. Retrieved from http://ejournal.staimtulungagung.ac.id/index.php/EDUKA SI/article/view/194

Kosasih, E. (2014). Strategi Belajar dan Pembelajaran (Implementasi Kurikulum 2013). Bandung: Yrama Widya.

Kurniadin, D., \& Machali, I. (2012). Manajemen Pendidikan Konsep \& Prinsip Pengelolaan Pendidikan. Jogjakarta: AR-Ruzz Media.

Machwe, P. (2000). Kontribusi Hindu terhadap ilmu pengetahuan dan peradaban. Denpasar: Widya Dharma.

Manullang, M. (2014). Manajemen Pembelajaran Matematika. Jurnal Pendidikan Dan Pembelajaran, 21(2), 208-214. Retrieved from http://journal.um.ac.id/index.php/pen didikan-danpembelajaran/article/view/7532/3445

Morocco, C. C. (2008). Supported Literacy for Adolescent: Transforming Teaching and Content Learning for The Twenty-First. San Fransisco: Jonh Wiley \& Sons,Inc.

Nadzir, M. (2013). Perencanaan Pembelajaran Berbasis Karakter. Jurnal Pendidikan Agama Islam, 2(2), 339-352. Retrieved from https://media.neliti.com/media/public ations/117338-ID-perencanaanpembelajaran-berbasis-karakt.pdf

Novalita, R. (2014). Pengaruh Perencanaan Pembelajaran Terhadap Pelaksanaan Pembelajaran (Suatu Penelitian terhadap Mahasiswa PPLK Program Studi Pendidikan Geografi FKIP Universitas Almuslim). Lentera, 14(2), 56-61. Retrieved from http://jurnal.umuslim.ac.id/index.php/ LTR1/article/download/201/124

Nurhaidah, M. I. M. (2015). Dampak Pengaruh Globalisasi Bagi Kehidupan Bangsa Indonesia. Jurnal Pesona Dasar, 3(3), 1-14. Retrieved 
from

http://www.jurnal.unsyiah.ac.id/PEA

$\mathrm{R} /$ article/view/7506

Nurohman, S. (2008). Peningkatan Thinking Skills Melalui Pembelajaran IPA Berbasis Konstruktivisme di Sekolah Alam. Jurnal Penelitian Dan Evaluasi Pendidikan, 9(1), 129-144. https://doi.org/10.21831/PEP.V11I1.1 423

Puryanti, E., \& Maryamah. (2015). Penerapan Metode Cooperative Script Terhadap Hasil Belajar Siswa Kelas V Pada Mata Pelajaran Ski Di Madrasah Ibtidaiyah Nurul Huda Kabupaten Oku Timur. Jurnal Ilmiah PGMI, 1(2). Retrieved from http://jurnal.radenfatah.ac.id/index.ph p/jip/article/view/666

Putra, N. (2015). Penilaian Autentik Mata Pelajaran Pendidikan Agama. Jurnal Al-Fikrah,

https://doi.org/http://dx.doi.org/10.31 958/jaf.v3i2.403

Rahayu, E. F. (2015). Manajemen Pembelajaran dalam Rangka Pengembangan Kecerdasan Majemuk Peserta Didik. Manajemen Pendidikan, 24(5), 357-366. Retrieved from http://ap.fip.um.ac.id/wpcontent/uploads/2015/05/volume-24no.-55-14.pdf

Ramadhani, H. S. (2017). Efektivitas Metode Pembelajaran Scl (Student Centered Learning) Dan Tcl (Teacher Centered Learning) Pada Motivasi Instrinsik \& Ekstrinsik Mahasiswa Psikologi Untag Surabaya Angkatan Tahun 2014 - 2015. Persona:Jurnal Psikologi Indonesia, 6(2), 66. https://doi.org/10.30996/persona.v6i1 .1302

Rohman, A. (2009). Memahami Pendidikan \& Ilmu Pendidikan. Yogyakarta: LaksBang Mediatama.

Rudiyanto, M. S., \& Waluya, S. B. (2010). Pengembangan Model Pembelajaran Matematika Volum Benda Putar Berbasis Teknologi Dengan Strategi
Konstruktivisme Student Active Learning Berbantuan CD Interaktif Kelas XII. Kreano, Jurnal Matematika Kreatif-Inovatif, 1(1), 33-44. Retrieved from http://journal.unnes.ac.id/nju/index.p $\mathrm{hp} /$ kreano/article/view/220

Ruja, I. N., \& Sukamto. (2015). Survey Permasalahan Implementasi Kurikulum Na- Sional 2013 Mata Pelajaran Ilmu Pengetahuan Sosial Sekolah Menengah Pertama Di Jawa Timur. Jurnal Sejarah Dan Budaya, xi(2), 193-199. Retrieved from http://journal.um.ac.id/index.php/seja rah-dan-budaya/article/view/5001

Rukayah, \& Ismanto, B. (2016). Evaluasi Manajemen Berbasis Sekolah Di Sekolah Dasar Negeri Kabupaten Semarang. Kelola Jurnal Manajemen Pendidikan UKSW, 3(2), 178-191. https://doi.org/https://doi.org/10.2424 6/j.jk.2016.v3.i2.p178-191

Rusman. (2017). Belajar \& Pembelajaran Berorientasi Standar Proses Pendidikan. Jakarta: Kencana.

Rusniati, R. (2015). Pendidikan Nasional Dan Tantangan Globalisasi: Kajian kritis terhadap pemikiran A. Malik Fajar. Jurnal Ilmiah Didaktika, 16(1), 105-128. https://doi.org/10.22373/jid.v16i1.58 9

S, M., Usman, N., \& Niswanto. (2017). Evektifitas Pelaksanaan Tugas Pengawas dalam Meningkatkan Mutu Pendidikan pada Sekolah Dasar Lingkungan UPTD Suku I Disdikpora Kota Banda Aceh. Prosiding Seminar Nasional Pascasarjana (SNP) Unsyiah, 154159. Retrieved from http://jurnal.unsyiah.ac.id/SNPUnsyiah/article/download/6941/5684

Sagala, S. (2011). Manajemen Strategik Dalam Peningkatan Mutu Pendidikan. Bandung: Alfabeta.

Samiudin. (2016). Peran metode untuk mencapai tujuan pembelajaran. Jurnal Studi Islam, 11(2), 94-97. 
Retrieved

from https://jurnal.yudharta.ac.id/v2/index. php/pai/article/view/407

Sidek, E. A. R., \& Yunus, M. M. (2012). Students' Experiences on using Blog as Learning Journals. Procedia Social and Behavioral Sciences, 67(November 2011), 135-143. https://doi.org/10.1016/j.sbspro.2012. 11.314

Soedijarto. (2008). Landasan dan arah pendidikan nasional kita. Jakarta: Kompas.

Subakti, Y. R. (2010). Paradigma Pembelajaran Sejarah Berbasis Konstruktivisme. Journal Seri Pengetahuan Dan Pengajaran Sejarah, 24, 38-70. Retrieved from https://www.usd.ac.id/lembaga/lppm/ f113/Jurnal

Historia Vitae/vol24no1april2010/Paradigma Pembelajaran Sejarah Yr Subakti.pdf

Sunarti, S. (2013). Hubungan Penerapan Metode Ceramah, Diskusi Dan Penugasan Dengan Hasil Pembelajaran Mata Pelajaran IPS / Sejarah Bagi Peserta Didik. Jurnal Ilmiah Pendidikan Sejarah IKIP Veteran Semarang, 1(1), 72-80. Retrieved from http://e-journal.ikipveteran.ac.id/index.php/dimensi/articl e/view/249

Surpi, N. K. (2017). Hadapi Tantangan Global, Lembaga Pendidikan Hindu Harus Jadi Gurukula Modern. Jurnal Penjaminan Mutu, 3(2), 171. https://doi.org/10.25078/jpm.v3i2.19 7

Suryapermana, N. (2017). Manajemen Perencanaan Pembelajaran. Tarbawi, 3(02), 183-193. Retrieved from https://www.neliti.com/publications/2 56452/manajemen-perencanaanpembelajaran

Susanti, M. (2015). Konstruktivisme Dalam Pembelajaran Matematika sekolah. Seminar Nasional Matematika dan Pendidikan Matematika UNY 2015, 1-25. Retrieved from http://seminar.uny.ac.id/semnasmate matika/sites/seminar.uny.ac.id.semna smatematika/files/banner/PM-84.pdf

Susanti, R. (2016). Implementasi Penilaian Autentik pada Mata Pelajaran Pendidikan Agama Islam dan Budi Pekerti. Jurnal Al-Fikrah, 4(1). https://doi.org/http://dx.doi.org/10.31 958/jaf.v4i1.409

Sutrisno, \& Suyadi. (2016). Desain Kurikulum Perguruan tinggi, Mengacu KKNI. Bandung: PT Remaja Rosdakarya.

Sutriyanti, N. K. (2017). Implementasi Kurikulum 2013 Pada Pembelajaran Pendidikan Agama Hindu Tingkat Sekolah Dasar di Kota Denpasar. Vidya Samhita, III(1), 97-113. Retrieved from https://ejournal.ihdn.ac.id/index.php/ vs/article/download/333/294

Syarifuddin, A. (2011). Penerapan Model Pembelajaran Cooperative Belajar Dan Faktor-Faktor Yang Mempengaruhinya. Ta'dib; Vol 16, No 01 (2011), 113-136. Retrieved from http://jurnal.radenfatah.ac.id/index.ph p/tadib/article/view/57/52

T, A. M., \& Purwoko, B. (2018). Studi Kepustakaan Mengenai Landasan Teori Dan Praktik Konseling Expressive Writing. Jurnal BK UNESA, 8(1), 1-8. Retrieved from https://jurnalmahasiswa.unesa.ac.id/i ndex.php/jurnal-bkunesa/article/view/22037

Trilling, S., \& Fadel, C. (n.d.). 21 st Century Skill: Learning for life in our Time. San Fransisco: Jonh Wiley \& Sons, Inc.

Wachyudi, K., Srisudarso, M., \& Miftakh, F. (2015). Analisis Pengelolaan dan Interaksi Kelas dalam Pengajaran Bahasa Inggris. Jurnal Ilmiah Solusi, 1(4), 40-49. https://doi.org/10.1017/CBO9781107 415324.004

Wayong, M. (2017). Menuju Era Globalisasi Pendidikan: Tantangan dan Harapan bagi Perguruan Tinggi di Tanah Air. 
Inspiratif Pendidikan, 6(2), 219. https://doi.org/10.24252/ip.v6i2.5223

Widyanto, I. P. (2019). Implementasi Manajemen Pembelajaran Saintifik di Institut Agama Hindu Negeri Tampung Penyang Palangka Raya. Satya Widya: Jurnal Stusi Agama, 2(1), 82-100. Retrieved from https://ejournal.iahntp.ac.id/index.php /satya-widya/article/download/56/42

Widyanto, I. P., Slamet, A., \& Prihatin, T. (2018). The Utilization of Whatsapp Application on Scientific-Based
Learning Management in Higher Education Institutions. Advances in Social Science, Education and Humanities Research (ASSEHR), 247(Iset), 241-245. https://doi.org/10.2991/iset18.2018 .51

Zakaria, S. F., \& Awaisu, A. (2011). SharedLearning Experience During a Clinical Pharmacy Practice Experience. American Journal of Pharmaceutical Education, 75(4), 75. https://doi.org/10.5688/ajpe75475 